\title{
A Study of the Form of Organizations: Toward an Integrative Framework of Population Ecology and Institutionalism
}

\author{
Sheng-Hsien Lee ${ }^{1}$ \\ ${ }^{1}$ Department of Business Administration, Yu Da University, Taiwan \\ Correspondence: Sheng-Hsien Lee, Department of Business Administration, Yu Da University, No. 168, \\ Hsueh-fu Rd., Miao-li County, 36143, Taiwan. Tel: 886-37-651-188-6028. E-mail: stephen@ydu.edu.tw
}

Received: January 18, 2012 Accepted: March 1, 2012 Online Published: May 16, 2012

doi:10.5539/ijbm.v7n10p108

URL: http://dx.doi.org/10.5539/ijbm.v7n10p108

\begin{abstract}
Does the form of organizations tend to show diversity or homogeneity? This paper begins with two contrasting questions: 'Why are there many organizational forms?' and 'Why are organizations similar?' Population ecology and institutional theory represent different lenses through which theorists use for interpreting these organizational phenomena. Each paradigm offers compelling concepts and arguments for supporting their own perspectives even though they seem to lead to contradictory results. This conceptual paper is an attempt to clarify the fundamental divergence of ecological and institutional approaches and proposes an integrated perspective for future empirical studies.
\end{abstract}

Keywords: organizational ecology, institutional theory, isomorphism

\section{Introduction}

There has been a proliferation of organization theory since Adam Smith brought about the notable principle of the division of labor. Among numerous academic quests, the question of 'Why does a firm exist?' raised by Nobel laureate, Ronald Coarse, has inspired researchers to look seriously at the very nature of the firm. Until the mid 1970s, the prominent approach in organization theory focused on adaptive change in organizations. On the other hand, inspired by the fundamental question: 'Where do organizational forms come from?' (Hannan and Freeman, 1977), organizational ecologists have attempted to explain how environmental conditions affect the relative abundance and diversity of organizations. Organizational ecologists seek explanations for organizational diversity at population and community levels of organizations and emphasize the rates of organizational founding and failure, and the creation and death of organizational populations as sources of increasing and decreasing diversity. The emergence of population ecology in organization theory represents the disposition of contingency theory from its hegemonic position.

The development of institutional theory is a reaction against the behavioral revolution of recent decades, which viewed collective political and economic behavior as the aggregate consequence of individual choice. The institutional approach tends to focus on a broad perspective: organizational structures and processes that are industry-wide, national or international scope. A common theme running through institutional theory is that of environmental influence over organizations. The starting point of new institutionalism in organizational analysis is the striking homogeneity of practices and arrangements found in corporations (DiMaggio and Powell, 1983). The persistent characteristics of organizations exemplify in the structures that are to some extent self-sustaining. The concept that best captures the process of homogenization is isomorphism, which occurs through three mechanisms: coercive, mimetic and normative isomorphism. The mechanisms of isomorphism offered by institutionalists provide a basis for legitimacy that reflects cultural alignment, normative support, or consonance with relevant rules of law.

A sharp contrast results from the different arguments about the pattern of organizations: diversity or homogeneity? DiMaggio and Powell (1983) deal with this controversy by introducing organization life cycle to reconcile the problem of diversity and homogeneity. They argue that organizational fields display considerable diversity in practice and form in the early stage of their life cycle. Once a field becomes well established, there is a relentless push toward homogenization. However, this line of argument fails to address the fundamental differences between institutional theory and an ecological approach in the level of analysis and dynamics of organization population. This paper addresses this seemingly contradictory issue by briefly reviewing some important 
concepts of these theories while formulating integrative analytical frameworks for future empirical tests.

\section{Organizational Ecology}

For any social system, actors discover better ways of doing things primarily through trial-and-error learning. Trials are variations on the existing ways of doing things. In addition, a distinguishing feature of human systems is that actors within them may observe the characteristics and practices of other social systems, evaluate their relationship to effective outcomes and try them within their own systems. In short, actors in social systems can imitate the characteristics of other systems. Variations that improve a system's fit to its environment or to achieve its ends more efficiently will be selected and retained in the system. Selection and retention ensure the identification and preservation of forms or processes that improve a system's fit, whether internally or with environments. Selection does not operate by comparing any one variation to a hypothetical best routine of excellence. What is understood as 'best' is only a relative construct, reflecting the emergence of one variation as better improving the system's fit. Selection can identify the variation that best improves the system's fit, and this variation can be retained and diffused over other similar systems. The concepts of variation, selection and retention as the major means of social evolution are well known and accepted in modern organization theory (Romanelli, 1999).

Variation is a source of heterogeneity of alterations on an existing form. Campbell (1974) proposed three characteristics of variations that are necessary for development or improvement of a social system. First, variations must be blind, in which the outcome of a variation must not be known in advance. Second, variations must be multiple. Lastly, most variations must fail to improve or distract the system's ability to survive. In other words, there exists a mechanism of selection that systematically eliminates variations which are less able to improve it.

Since the 1970s, organizational ecologists have been developing conceptual tools and analytical techniques for studying organization/environment relationships by focusing on organizational populations. Ecological research typically begins with three observations: (1) diversity is a property of aggregates of organization, (2) organizations often have difficulty divesting and executing changes fast enough to meet the demands of uncertain environments, and (3) the community of organizations is rarely stable, that is, organizations arise and disappear continually. Here, community refers to a combination of interacted populations and is equivalent to organizational field by definition (DiMaggio and Powell, 1983). Organizations, populations and communities of organizations constitute the basic elements of an ecological analysis. The study of population dynamics focuses on the life events of organizations - their births and deaths. Several fundamental concepts of the ecological approach are reviewed briefly below.

\subsection{Organizational Form}

A form is a set of stable routines for accomplishing organizational action and the organizational form represents a formula for doing business. Organizations display inertia to the extent that variables describing their strategic and structural features change at relatively slow rates. Organizational managers often face a wide variety of constraints that limit their ability to make changes of various kinds that occur as relatively abrupt modifications in the organization's mode of operating. These changes are likely to be abrupt because strategy, structure, and patterns of human behavior are linked. Resistance to piecemeal adaptation is likely to occur (Freeman and Boeker, 1984).

\subsection{Organizational Population}

The form is observable in structure, in distinctive operating characteristics and in marketing and technical strategies. The collection of firms corresponding to each form is a population. The expansion or contraction of populations provides important contextual information for strategists and they often survey the market or industry they are entering in order to identify what kind of firms operate there, those which are flourishing, and those which are failing.

\subsection{Niche}

An organizational form's niche is a mix of the social, economic and political conditions that can sustain the functioning of organizations that embody a particular form (Hannan and Carroll, 1995). The organizational form represents a combination of resources and ranges of resources that can be employed by organizations. Form and niche are therefore defined with reference to each other. Hannan and Freeman (1977) use niche-width theory to formulate a model of the differential survival capabilities of specialist organizations, which concentrate on ways to exploit a narrow range of potential customers, and generalist organizations, which seek to appeal to the average consumers who demonstrate adaptive tolerance for more widely varying environmental conditions. 
Potential competition for each organization is measured using overlap density, the aggregate overlap of an organization's resource requirements with those of all others in the population (Baum, 1999).

\subsection{Entrepreneurship}

Entrepreneurship implies strategies. Most entrepreneurs seem to imitate existing models of successful examples for organizing, rather than starting a completely new firm because it reduces the risk of death at founding by increasing the reliability of the performance of the organization. Moreover, following an established form makes the new organization more accountable to other organizations with which it carries out transactions. Organizations using a successful strategic formula tend to become more numerous, which leads to the expansion of the associated population.

Changes in organizational populations involve four critical processes: variation, selection, retention, and competition (Aldrich, 1979). Variations are human behaviors including any kind of intentional or blind change. Individuals generate variations in technical and management competencies in their efforts to adjust their organization's relation to the environment. Some variations prove more beneficial than others in acquiring resources and are hence are selected positively by managers inside organizations, and by investors, customers and government regulators in the external environment (McKelvey, 1994; Meyer, 1994). Successful variations are retained as surviving organizations come to be characterized by them. In contrast to adaptation approaches, which explain changes in organizational diversity via cumulative strategic choices and changes to existing organizations, ecological approaches highlight the creation of new organizations and the demise of old ones.

\section{Diversity or Homogeneity: Environment}

A common theme running through institutional theory is environmental influence over organizations. Most of the verbs used to describe organization-environment relations have explicit implications in which environments 'dominate' or 'overpower' organizations and in this respect, institutional theory resembles population ecology (Aldrich, 1999). Organizations only change when external contingencies change. This aspect of institutional theory turns organizations into 'passive collection points' for the rules and agendas institutionalized at higher levels of societies (Hirsch, 1983). In this light, institutional theory concentrates more on the reproduction than on the creation or transformation of organizations.

Institutional theorists have taken variation primarily as external in origin, generated as organizations are forced to respond to, adapt to, or imitate the normative and regulatory currents in their environments. For some analysts, variation arises from organizations responding to events at higher levels of analysis, such as population and community changes (Zucker, 1987). When environments are treated as institutions, theorists have typically taken a reproductive theme focusing on how system or sector-wide social facts are copied on the organizational level. As a consequence of adopting externally-generated facts in pursuit of legitimacy, the technical core of an organization is decoupled from directed evaluation on the grounds of efficiency. On the other hand, when organizations have been treated as institutions, theorists have adopted a generative theme, examining the creation of new cultural elements by organizations. Small groups and managers often acquire new facts by copying other organizations. Organizations adapt their structures to conform to an institutionalized pattern supported by powerful legitimating forces outside themselves (DiMaggio and Powell, 1983). Furthermore, when an organizational form falls out of favor and loses legitimacy, actors cease adopting that form and move on to others. Therefore, one outcome of successful imitation is enhanced organizational stability. Success comes from imitating others, rather than from an organization's own technical achievements (Aldrich, 1999).

Institutional theorists emphasize the forces that create and maintain organizations as coherent, integral units, focusing on large, long-lived organizations. They are forces such as socialization and characteristic leadership that promote the diffusion of shared meaning, increasing the successful reproduction of an organization (Aldrich, 1999).

Institutional theory emphasizes that organizations must conform to institutionalized rules and requirements if they are to receive support and be perceived as legitimate. However, the detrimental convergence on a particular set of socially agreed-upon practices will engender some low-probability trials that will dramatically demonstrate a new and better practice.

How is it possible that isomorphism and diversity are compatible concepts? DiMaggio and Powell (1983) deal with this controversy by introducing organization life cycle to reconcile the problem of diversity and homogeneity. They argue that organizational fields display considerable diversity in practice and form in the early stage of their life cycle. Once a field becomes well established, there is a relentless push toward homogenization. Here, organizational field refers to those organizations that include key suppliers, resource and 
product consumers, regulatory agencies, and other organizations that produce similar products or services.

DiMaggio and Powell (1983) also emphasize that the level of analysis exhibits the totality of relevant actors and comprehends the importance of connectedness and structural equivalence. Organizations may try to change frequently, but when reaching a certain extent in the structuration of an organizational field, the aggregate effect of organizational change will lessen the extent of diversity within the field. The concepts of diversity initially asked by population ecologists, and the homogeneity proposed by institutional theorists, seem to find their convergence through life cycle perspective (see Figure 1).

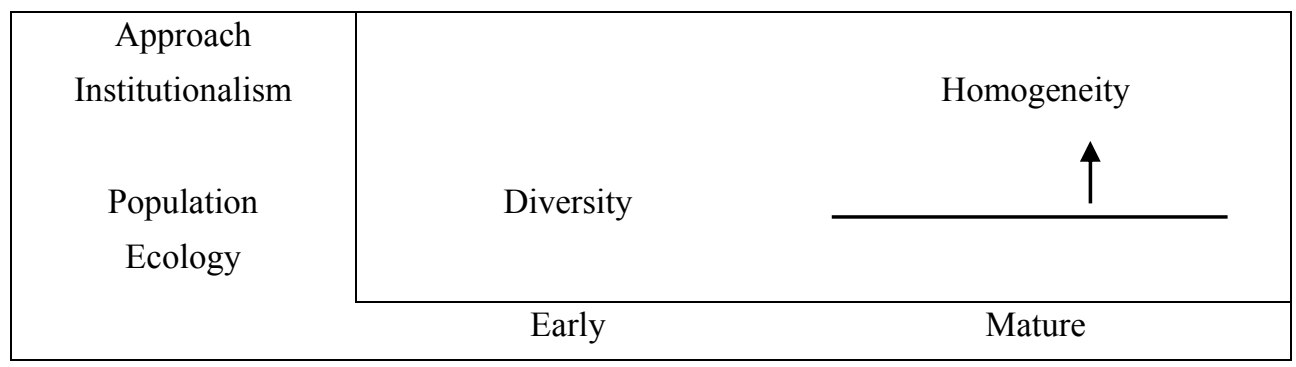

Figure 1. DiMaggio and Powell's (1983) Conceptual Model

However, the population ecologists' natural environment is exogenous, in that the selection process is relentlessly operated. The diversity of environment manifested by the various niches and its carrying capacity projects the diversity of organizational forms. For the institutionalists, the environment is constructed by collective actions and is, therefore, institutionalized for imposing constraints on actors as a whole. Since the perspective of environment differs drastically, a point of divergence thus arises. Although DiMaggio and Powell's (1983) acclaimed efforts in integrating ecological and institutional approaches exhibit some face-value connection, the fundamental divergence remains to be reconciled. Unless one can develop the bridging logic for the generation of an isomorphic environment, the eventual homogeneity of populations will still be open to the debate. Figure 2 illustrates a juxtaposition of ecological and institutional approaches.

\begin{tabular}{|c|c|c|c|c|}
\hline Approach & Level & Pattern & & \\
\hline Population & Community & Diversity & $\longrightarrow$ & Diversity \\
\hline Ecology & & \multicolumn{3}{|c|}{ Population dynamics } \\
\hline Institutional & Organizational & \multirow[t]{2}{*}{ Diversity } & & \multirow[t]{2}{*}{ Homogeneity } \\
\hline \multirow[t]{2}{*}{ Theory } & Field & & Adaptation & \\
\hline & & Early & & Mature \\
\hline
\end{tabular}

Figure 2. A Juxtaposition of Ecological and Institutional Approaches

\section{Diversity or Homogeneity: Organization}

\subsection{Adaptation}

The 1960s saw a development of contingency perspective. Environmental uncertainty pulls organizations in different directions as different parts of the organization seek to adjust to their own sub-environment. Such differentiated adaptation creates problems of integration which in turn lead to the development of new structures (Lawrence and Lorsch, 1967). According to this view, organizations are not regarded as passive actors and the behaviors of their managers are seen as largely reactive. Some major branches of organizational theory in this period stress the proactive behavior of organizations, for example, the resource dependence theory which 
explains organizational structures as a result of the strategic actions taken by managers to lessen dependence on other organizations that provide key resources (Pfeffer and Salancik, 1978).

During the 1960s and 1970s, many leading organizational theorists began to view organizations as merely the tools used by managers in taking strategic action to advance their interests (Hannan and Freeman, 1989). When organizational structures are treated as simple tools, organizations become less relevant in the processes of social change; with the rise of a managerial emphasis, the role given to unplanned and unconscious behavior dwindled. Therefore, organizations are depicted by organization and strategy researchers as consciously designed for the pursuit of explicit goals. This line of literature views strategy as the willful choice of top managers while if organizations are plastic, only the intentions of organizational elites matter.

\subsection{Imitation}

Why reinvent the wheel? Past literature shows a pervasive belief that successful change in one organization can be achieved through copying the attributes or practices of another organization. Organizational theorists have observed a profound similarity of organizational routines and structures over a large number of organizations. It is imitation processes, including direct learning and imitation by organizations, that contribute to much of this homogeneity within organizational forms (Hannan and Freeman, 1984).

In the popular organizational literature, a similar concept of copying is found in the idea of 'benchmarking', deriving from total quality management. It refers to processes by which managers in one organization analyze systems and routines of another organization for potential adoption in the first organization. Moreover, best practices are being sought in search of excellence. This line of thought treats imitation as an effective route to improved organizational performance. Therefore, copying represents a potentially efficient means for introducing new practices, or variations, into an organization's activities and routines. Imitation may avoid some of the costs of trial-and-error learning and may also expand an organization's repertoire of potentially effective variations which might not have been discovered through the operation of their own systems and processes. Copying is a potentially effective means for introducing variation into an organizational system. The potential benefits of copying are simply evident. The dynamics of imitation are shown graphically in Figure 3.

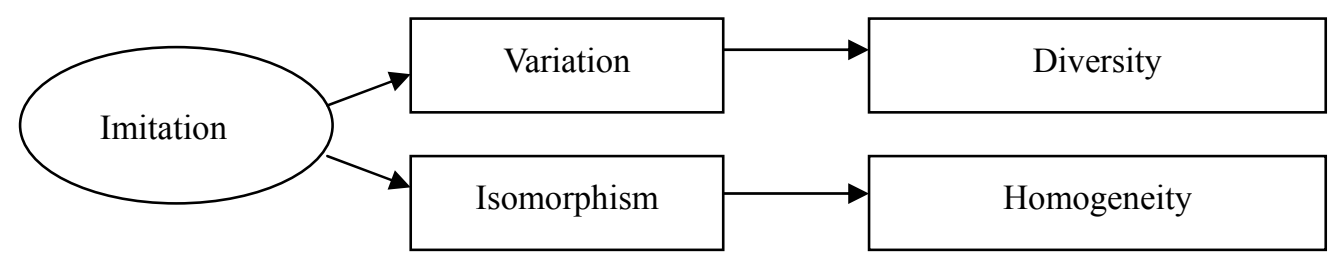

Figure 3. The Dynamics of Imitation

Imitation is important in retaining or sustaining existing routines, practices, and divisions against the forces of change in the dynamics of population level change. Critics of institutional theory claim that its emphasis on imitation limited its ability to account for variation and change. Institutional theorists emphasize that inter-organizational imitation produces homogeneity among practices (DiMaggio and Powell, 1983; Meyer and Rowan, 1977). However, Miner and Raghavan (1999) argue that repeated inter-organizational imitation acts as a selection mechanism to change the nature and mix of routines enacted in a population of organizations. They found factors which moderate the impact of imitation and hence in some cases generate new mixes of routines in populations of organizations. The moderating factors include the features of (1) the imitator, (2) the practice imitated, (3) the exact sequence of steps involved in imitation, and (4) features of the imitation context. There are many ways that imitation can produce new mixtures of routines.

Analysts seem to assume that competition represents the most important force for selection over organizations and routines. The most fundamental principle of modern capitalism is that organizations compete, with some surviving and some failing. Therefore, a powerful determinant of the mix of routines in a population will be the competitive forces, which underlies the ecological approach. Organizations may observe their competitors and try to imitate their successful routines as a part of the competitive process; however, competition does not necessarily involve imitation at all. A group of organizations can sense the effects of new entrants through reduced demand without even knowing the nature of that competition. The focal organizations may change their own behavior in response to the reduced demand but base their actions on their own experience. In this light, competitive interaction does not necessarily involve imitation. Likewise, imitation does not necessarily involve 
competition. For example, a group of organizations free from competition may engage in imitation of various kinds. Imitation thus represents a distinct potential engine of selection (Miner and Raghavan, 1999).

Miner and Raghavan (1999) further propose three specific modes of learning through copying at the population level: (1) frequency imitation: copying the most common organizational routine, (2) trait imitation: copying the routine of some organizations based on a trait, such as size, prestige or similarity, (3) outcome imitation: copying routines that appear to have good consequences for other organizations. In effect, organizations may imitate the practices of other organizations because they are prevalent in the population, which implies effectiveness, or because they are associated with positive outcomes, or because they exhibit desirable characteristics independent of any relationship to performance. The imitating organization acquires the trial-and-error experience of another organization without investing resources in its own trials and the copied routines or practices have exhibited their ability to improve an organization's environmental fit. However, internally generated variations will not gain the kind of legitimacy held by variations that are socially validated in the external environment.

Imitation is not the only way that novel variations can be introduced, and it may not be always good for organizational development. Imitation provides a ready-made rationale for expending resources on certain trials rather than others, which constrains an organization's search for other trials (Romanelli, 1999). Variations that could have been developed within the organization's own idiosyncratic system of knowledge and which could have proved more efficient may be neglected. Furthermore, when imitation has become an important source of legitimacy, the chances for an organization to introduce and try new variations may be seriously constrained.

Conversely, structural inertia theory proposed by population ecologists emphasizes that existing organizations often have difficulty changing strategy and structure quickly enough to meet the demands of an uncertain environment. The structures and routines of existing organizations represent vested interest and power structures, whereby the self-interested individuals may tend to resist any potential structural change which might put their privileges at risk. Major organizational innovations occur early in the life-histories of organizations and populations where structuration is at the initial stage. Therefore, organizational change and variability reflect primarily relatively inert organizations replacing each other. Table 1 summarizes the fundamental differences of the ecological and institutional approaches. The effect of imitation diverges according to whether it generates more variations across organizational forms through benchmark or spillover, or reduces variations via isomorphic tendency. The assumption of the extent of organizational flexibility underlies the controversy: diversity or homogeneity.

Table 1. The Characteristics of Ecological and Institutional Approaches

\begin{tabular}{ccc}
\hline Level & Population Ecology & Institutional Theory \\
\hline Community/Field & Diversity & Homogeneity \\
Population/Form & Variation & Isomorphism \\
Organization & Structural Inertia & Adaptation \\
\hline
\end{tabular}

\section{Conclusion}

This paper began with two contrasting questions: 'Why are there many organizational forms?' and 'Why are organizations similar?' Population ecology and institutional theory represent different lenses through which theorists interprets these organizational phenomena. Each offers compelling concepts and arguments for supporting their perspectives even though they seem to lead to quite contradictory results, hence the quest of this paper: Diversity or Homogeneity?

Some theorists treat the relationship between ecological and institutional theory as complementary, and propose their synthesis into a single explanatory framework (Hannan and Carroll, 1992). Others conceive that the relationship between them is not only complementary but also hierarchical by treating institutional theory as contextual to ecological research (Tucker et al., 1992). The institutional environment may prescribe the environmental selection criteria. Ecological literature in institutional processes typically compares founding and failure rates across organizational populations or over time as the institutional environment of a particular population changes. Organizational structures may be imposed by a higher authority as a result of the coercive power of government, or authorized by a higher authority when seeking its approval. Moreover, structures may be induced when a higher authority offers incentives for recipients of funding, or acquired when organizations deliberately choose a structural model via imitative or normative isomorphism (DiMaggio and Powell, 1983). 
Isomorphism is a constraining process that forces one unit in a population to resemble other units facing the same set of environmental conditions. In other words, it is the process of homogeneity.

In this paper, attempts have been made to clarify the fundamental divergence of ecological and institutional approaches. First, the concepts formulated by these approaches are inevitably restricted in their use as they refer to different levels of analysis (for a summary, see Table 1). Second, the relationship of organization/environment requires careful attention before any attempts to reconcile these two approaches. For example, the contrasting perspectives of natural environment and constructed environment undoubtedly lead to the development of incompatible theoretical backbones. Third, the assumption of structural inertia seriously restrains an organization's adaptability in response to environmental change. As a result, the expansion or contraction of a population reflects the birth or death of a certain organizational form. To reconcile the ecological and institutional approaches, the life cycle perspective offered by DiMaggio and Powell (1983) is obviously in need of more fine-grained theoretical developments. Figure 2 represents an attempt to advance DiMaggio and Powell's theory. In asking 'where do organizational forms come from?' Hannan and Freeman (1986) modified their earlier concept of population based in biological ecology in favor of social construction. Furthermore, Hannan's (1986) model of population growth includes new populations' needs for material resource mobilization as well as their dependence on institutional processes that legitimate them. Obviously, the broad reach of the institutional approach has opened up possibilities for collaboration with population ecology.

\section{References}

Aldrich, H. (1979). Environment and organization. Englewood Cliffs, NJ: Prentice Hall.

Aldrich, H. (1999). Organizations evolving. Sage Publications.

Baum, J. A. C. (1999). Organizational ecology. In Stewart R. Clegg and Cynthia Hardy (eds.), The studying organization. Sage Publications.

Campbell, D. T. (1974). Unjustified variation and selective retention in scientific discovery. In F. J. Ayala and T. Dobzhansky (eds.), Studies in the philosophy of biology. London: Macmillan.

DiMaggio, P., \& Powell, W. (1983). The iron cage revisited: institutional isomorphism and collective rationality in organizational field. American Sociological Review, 48(2), 147-160. http://dx.doi.org/10.2307/2095101

Freeman, J., \& Boeker, W. (1984). The ecological analysis of business strategy. In Glenn Carroll, \& David Vogel (1984), Strategy and organization. The Regents of the University of California.

Hannan, M. T. (1986). A model of competitive and institutional processes in organizational ecology. Technical Report No. 86-13. Department of Sociology, Cornell University.

Hannan, M. T., \& Carroll, G. (1992). Dynamics of organizational populations: Density, legitimation and competition. New York: Oxford University Press.

Hannan, M. T., \& Freeman, J. (1977). The population ecology of organizations. American Journal of Sociology, 82(5), 929-964. http://dx.doi.org/10.1086/226424

Hannan, M. T., \& Freeman, J. (1984). Structural inertia and organizational change. American Sociological Review, 49(2), 149-164. http://dx.doi.org/10.2307/2095567

Hannan, M. T., \& Freeman, J. (1986). Where do organizational forms come from? Sociological Forum 1(1), 50-72. http://dx.doi.org/10.1007/BF01115073

Hannan, M. T., \& Freeman, J. (1989). Organizational Ecology. The President and Fellows of Harvard College.

Hirsch, P. M. (1997). Sociology without social structure: Neo-institutional theory meets brave new world. American Journal of Sociology, 102(6), 1702-1723. http://dx.doi.org/10.1086/231132

Lawrence, P. R., \& Lorsch, J. W. (1967). Organizations and environments: Managing differentiation and integration. Boston, MA: Harvard Business School Press.

McKelvey, B. (1994). Evolution and organizational science. In Joel A. C. Baum and J. V. Singh (eds.), Evolutionary dynamics of organizations. New York: Oxford University Press.

Meyer, J., \& Rowan, B. (1977). Formal structure of organizations as myths and ceremony. American Journal of Sociology, 83(2), 340-363. http://dx.doi.org/10.1086/226550

Meyer, M. W. (1994). Turning evolution inside the organization. In Joel A. C. Baum and J. V. Singh (eds.), Evolutionary dynamics of organizations. New York: Oxford University Press.

Miner, A. S., \& Raghavan, Sri V. (1999). Interorganizational imitation: a hidden engine of selection. In Joel A. C. 
Baum and Bill MeKelvey (eds.), Variations in organization science. Sage Publications.

Pfeffer, J., \& Salancik, G. R. (1978). The external control of organizations. New York: Harper and Row.

Romanelli, E. (1999). Blind (but not unconditioned) variation: Problems of copying in sociocultural evolution. In Joel A. C. Baum, \& Bill MeKelvey (eds.), Variations in organization science. Sage Publications.

Tucker, D. J., Baum, J. A. C., \& Singh, J. V. (1992). The institutional ecology of human service organizations. In Y. Hasenfeld (eds.), Human service organizations. Newbury Park, CA: Sage.

Zucker, Lynne G. (1987). Institutional theories of organizations. Annual Review of Sociology, 13, $443-464$. http://dx.doi.org/10.1146/annurev.so.13.080187.002303 